\title{
Pulsed phase thermography of Aluminum laminates: neural network investigation
}

\author{
by Y. Largouët, S. Vallerand and X. Maldague
}

Electrical and Computing Engineering Dept., Université Laval, Québec, Qc Canada G1K 7P4,ph:

(418)656-2962, fax: (418) 656-3594, e-mail: maldagx@gel.ulaval.ca

\section{Abstract}

In this paper, a brief review of Pulsed Phase Thermography (PPT) principles are recalled followed by investigations of a neural network applied to quantitative depth discrimination in PPT in the case of aluminum specimens. The paper includes theory and experimental investigations.

\section{Pulsed Phase Thermography}

Pulsed Phase Thermography (or PPT) has been recently introduced as a signal processing method in infrared thermography for non-destructive evaluation [1]. PPT principle is as follow. The specimen is flash-heated and the subsequent specimen surface temperature decay is recorded. The Fast Fourier Transform (FFT) of the temporal temperature decay is next performed on a pixel per pixel basis. This allows to extract phase and amplitude images at specific frequencies. PPT has some interesting features in term of defect detection capabilities as it shares some characteristics of both conventional pulsed infrared thermography [2] and lockin thermography [3,4]. More details can be found in [5], Figure 1 illustrates PPT principle.

\section{Thermal model}

In order to predict specimen behaviour, analyze phase evolution and thus establish the neural network architecture, a simple 1-D thermal model was developed. It is based on the equation (refer to $[6,7]$ ):

$$
\frac{d^{2}}{d x^{2}} T(x, t)=\frac{1}{\alpha} \frac{\partial}{\partial t} T(x, t)
$$

Solving this equation gives temperature $T$ in the material for depth $x$ (remaining material thickness in case of defects of the flat-bottom hole types) and time t. Figure 2 shows various simulated phase spectra as function of frequency and for different depths. On this graph, three different depths corresponding to possible defects $(2.2,4.4,5.1 \mathrm{~mm})$ are pinpointed.

\section{Experimental setup}

The standard experimental apparatus includes a Cincinnati Electronics 160 FPA camera (short wave: $2-5 \mu \mathrm{m}, 20^{\circ}$ lens) with a workstation-based computer (Sun microsystem Sparc 4) and dedicated software. The image acquisition rate is 54 images per second and the heating system comprises two high power flashes (15 ms duration, $6.4 \mathrm{KJ}$ ) with back reflector.

\section{Neural network (NN)}

Neural networks (NN) are known for their capacity to deal with complex non linear problems with only partial noisy data available. NN are thus advantageous to rely on to perform the inverse problem of interest here which consists to extract depth from phase information in PPT. Previous works reported did not used phase information as NN inputs but 
thermal contrast instead [8-10]. Interested readers are referred to reference [11] for an introduction to NN.

After many trials using the thermal model discussed previously we settled for a multilayer perceptron with back-propagation learning and one hidden layer in a $9 \times 17$ configuration.

This architecture was trained with 325 filtered experimental data sets corresponding to depth values of 0.04 to $10 \mathrm{~mm}$. The experimental set-up discussed previously provides 64 thermograms and thus 64 phase and 64 amplitude images (filtering: temperature data sliding Gaussian window + phase spectra - simple averaging in a $3 \times 3$ kernel). Due to the symmetry property of the Fast Fourier Transform, only 32 of these are relevant and serve as inputs to the NN. The single neuron output provides the depth and the analysis proceeds pixel per pixel. Various tests were performed on samples different than those used at the training stage.

\section{Results}

Experiments were conducted to investigate the potential of the developed NN. For instance, on Figure 3, results of the NN network are shown in the case of a plate of aluminum of total thickness of $1.06 \mathrm{~mm}$ and with three $25 \mathrm{~mm}$-diameter flat-bottom hole defects. From left to right the hole depths (remaining material thickness) are: $0.61,0.78$ and $0.88 \mathrm{~mm}$ (coded in term of percent of corrosion on the gray scale under the Figure, respectively: $42 \%, 26 \%, 17 \%)$.

In order to assess the validity of such results the error was computed, picture element by picture element from the known defect geometry. For this image, the percent of error is $17 \%$ ( $0 \%$ means no error, $100 \%$ means full-error). A picture element is said to be in error if computed depth is different than real depth.

\section{Conclusion}

This study indicates it is possible to obtain quantitative information from phase value information obtained by PPT. The method used for data inversion was based on a neural network perceptron.

\section{Acknowledgement}

This work is supported by the Natural Sciences and Engineering Research Council of Canada.

\section{REFERENCES}

[1] MALDAGUE (X.), MARINETTI (S.) - Pulsed Phase Infrared Thermography. J. Appl. Phys., 79, 1996, p. 2694-2698.

[2] MALDAGUE (X.) - Nondestructive evaluation of materials by infrared thermography. London, Springer-Verlag, 224 p. (1993)

[3] BUSSE (G.), WU (D.), KARPEN (W.) - Thermal wave imaging with phase sensitive modulated thermography. J. Appl. Phys., 71, 1992, p. 3962-3965.

[4] BUSSE (G.) - Nondestructive evaluation of polymer materials. NDT \&E Int'l, 27, 1994, p. 253-262.

[5] MALDAGUE (X.), COUTURIER (J.-P.) - Review of Pulsed Phase Thermography. IV Advanced Infrared Technology and Applications Workshop, L.R. Abbozzo, G.M. Carlomagno, C. Corsi eds, Atti della Fondazione G. Ronchi, Firenze, 1997 [in press, 1998]

[6] LARGOUET (Y.) - Rapport de stage sur la thermographie de phase pulsée. Université Laval, Laboratoire de Vision et Systemes Numériques, 77, p., 9-1997. [in French] 
[7] MACLACHLAN-SPICER (J. W.), KERNS (W. D.), AMODT (L. C.), MURPHY (J. C.) Time-resolved infrared radiometry (TRIR) of multilayer organic coatings using surface and subsurface heating. Thermosense XIII, Proc. SPIE, G. S. Baird ed., 1467: 1991, p. $311-$ 321.

[8] PRABHU (D. R.), HOWELL (P. A.), SYED (H. 1.), WINFREE (W. P.) - Application of artificial neural networks to thermal detection of disbonds. Review of Progress in Quantitative NDE, D.O. Thompson, D.E. Chimenti eds, 11B: 1331-13382 (Plenum Press, 1992).

[9] BISON (P. G.), BRESSAN (C.), DI SARNO (R.), GRINZATO (E.), MARINETTI (S.), MANDUCHI (G.) - Thermal NDE of delaminations in plastics by neural network processing. Proc. of Quantitative Infrared Thermography (QIRT 94), Eurotherm Seminar 42, Éd. Eur. Thermique et Industrie), D. Balageas, G. Busse, G.M. Carlomagno eds, 1994 , p. 214-219.

[10] SANTEY (M. B.), ALMOND (D. P.) - An artificial neural network interpreter for transient thermography image data. NDT \& E Int., 30[5]: 1997, p. 291-295.

[11] LAU (C.), editor. - Neural Networks. IEEE Press, 327 p, 1991.

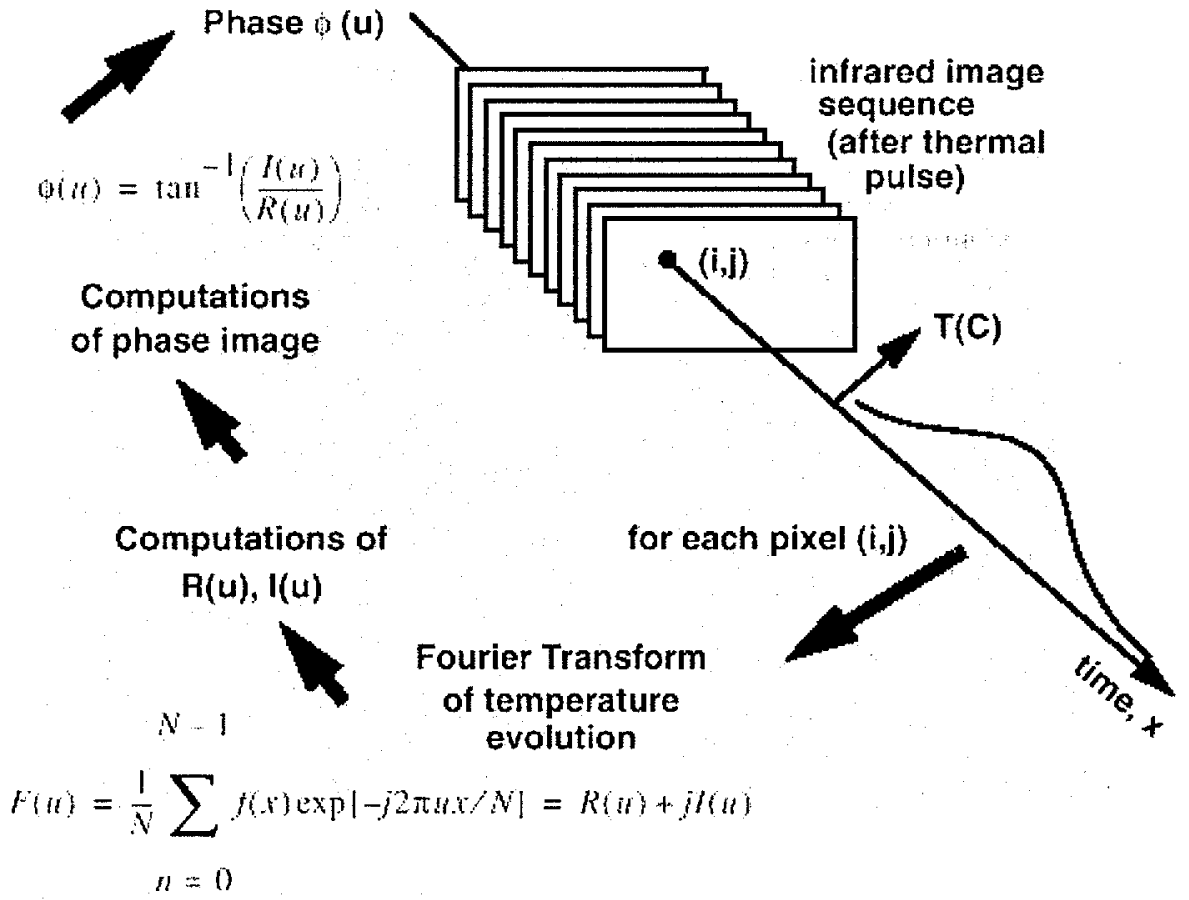

Fig. 1. Pulsed Phase Thermography (PPT) principle 


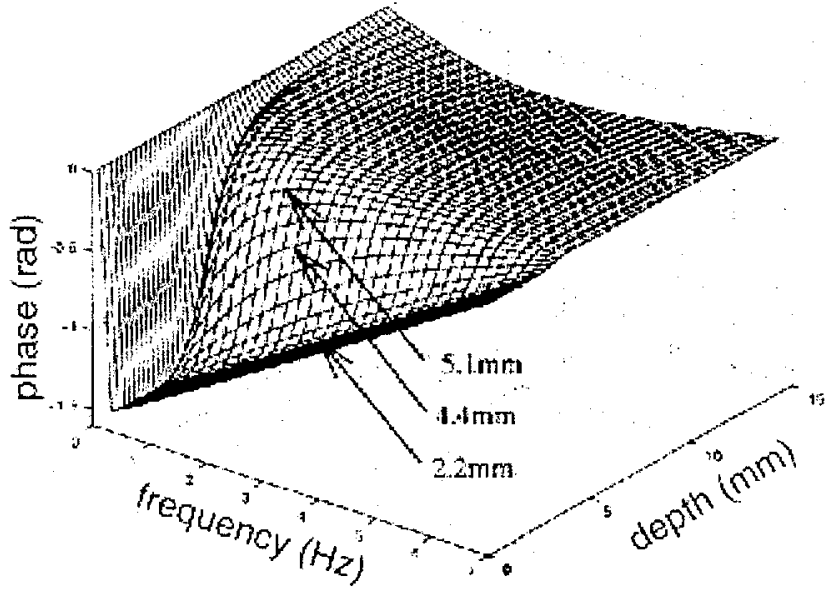

Fig. 2. Simulated phase spectra for aluminum
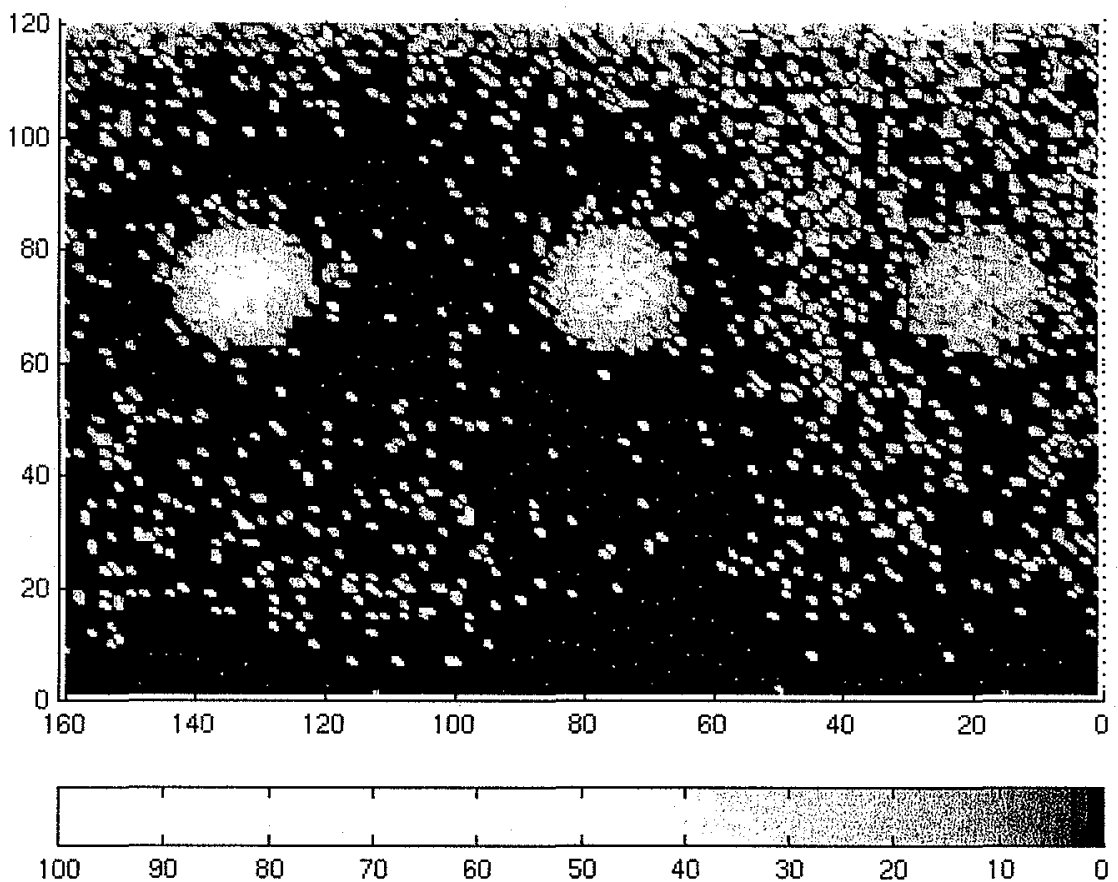

Fig. 3. Results from perceptron neural network in the case of an aluminum plate with three flat-bottom holes. Retrieved percent of corrosion is coded by shades as indicated in the color bar). 